\title{
Effect of Inhibitors on Zeaxanthin Synthesis in a Flavobacterium
}

\author{
By J. C. B. McDERMOTT,* G. BRITTON AND T. W. GOODWIN \\ Department of Biochemistry, University of Liverpool, Liverpool, L69 $3 B X$
}

(Received I 4 February I973)

\begin{abstract}
SUM MAR Y
Several substances have been tested for inhibitory effects on carotenoid biosynthesis in Flavobacterium RI519, an organism which normally produces zeaxanthin $(\beta, \beta$-carotene-3,3'-diol) as essentially its only carotenoid. Diphenylamine, several mixed-function oxidase inhibitors (SKF 525A, SKF 330 I A, SKF $7997 \mathrm{~A}_{3}$, metopirone base, diphenylpropylacetic acid, piperonyl butoxide), several alkaloids (atropine, brucine, hyoscyamine, pilocarpine, quinidine, quinine, scopolamine, strychnine), some substitued pyridines (pyridine, 3-picoline, 3-ethylpyridine, 5-ethyl-2-methylpyridine) and morpholine showed no specific inhibitory effects. In cultures grown in the presence of $\mathrm{CaCl}_{2}, \beta$-carotene $(10 \%)$ and $\beta$-cryptoxanthin $(10 \%$ ) partly replaced zeaxanthin. Nicotine specifically inhibited zeaxanthin synthesis. Lycopene (in $5 \mathrm{~mm}$-nicotine) and rubixanthin (in I mM-nicotine) accumulated as the new main pigments; $\left[2{ }^{14} \mathrm{C}\right]$ mevalonic acid was efficiently incorporated into both. Nicotine thus inhibited the cyclization reaction in carotenoid biosynthesis in Flavobacterium RI5I9 as in other organisms; in zeaxanthin biosynthesis cyclization appeared to precede hydroxylation. Similar inhibitory effects were produced by $(+)$ and $(-)$ nicotine and by nor-nicotine, but not by the closely related anabasine, myosmine, $\beta$-nicotyrine and nor-nicotyrine.
\end{abstract}

\section{INTRODUCTION}

The biosynthesis of carotenoid pigments in plants and micro-organisms has been extensively studied, and is the subject of several recent reviews (Porter \& Anderson, I967; Britton, 1971; Goodwin, 1971). The main outline of the pathway leading to the carotene hydrocarbons appears to be reasonably well established and, although the biosynthesis of the oxygenated carotenoids (xanthophylls) has not been studied in detail, it is generally assumed that these are formed from the carotenes at a late stage in the biosynthetic sequence. The availability of a Flavobacterium strain (R I I I9) which produces as virtually the only carotenoid large amounts of zeaxanthin $\left(\left(3 R, 3^{\prime} R\right)-\beta, \beta\right.$-carotene- $3,3^{\prime}$-diol $)$ (I) has provided the opportunity to study xanthophyll biosynthesis in detail. Thus it has been shown (J. C. B. McDermott, F. J. Leuenberger, G. Britton \& T. W. Goodwin, unpublished results) that the stereochemistry of zeaxanthin biosynthesis in Flavobacterium RI5I9 is the same as in higher plant systems studied (Walton, Britton \& Goodwin, 1969). However, under normal conditions, zeaxanthin constitutes at least $99 \%$ of the total carotenoid in Flavobacterium RI5I9, so that it is not possible to identify any possible intermediates in zeaxanthin biosynthesis, or to try to establish precursor-product relationships between different carotenoids.

In order to overcome this difficulty, we have examined the effect on zeaxanthin production in Flavobacterium RI5I9 of several compounds considered as possible inhibitors of carotenoid synthesis, including a number of compounds known to inhibit the production of the

\footnotetext{
* Present address: Department of Botany, University of Liverpool, Liverpool, L69 3BX.
} 
normal carotenoids by other organisms. In particular, conditions were sought under which the formation of zeaxanthin was specifically inhibited, and other carotenoids, possibly intermediates in zeaxanthin biosynthesis, accumulated.

\section{METHODS}

Strains. Flavobacterium strains R I 5 I9 ( = oI 47), R I 534, R I 552 and R I 560 were kind gifts from F. Hoffmann-La Roche \& Co. Ltd, Basle, Switzerland.

Compounds tested as inhibitors of carotenoid production. Diphenylamine, nicotine hydrogen $(+)$ tartrate, morpholine and 3-picoline were purchased from B.D.H. Ltd, Poole, Dorset, 5-ethyl-2-methylpyridine was obtained from Eastman Organic Chemicals, Rochester, New York, U.S.A., piperonyl butoxide and 3-ethylpyridine from Koch-Light Laboratories Ltd, Colnbrook, Buckinghamshire and $\beta$-nicotyrine (Fluka) from R. Emmanuel Ltd, Wembley, Middlesex.

Samples of atropine sulphate, brucine sulphate, hyoscyamine sulphate, pilocarpine hydrochloride, quinidine sulphate, quinine sulphate, scopolamine hydrobromide and strychnine sulphate were obtained by our colleague Dr A. Ben-Aziz from Plantex Ltd, Nathanya, Israel, through the courtesy of Dr Pfeffer.

Samples of nor-nicotine, $\beta$-nicotyrine, nor-nicotyrine, myosmine and anabasine picrates were kindly provided by $\operatorname{Dr}$ T. A. Scott, Department of Biochemistry, University of Leeds. $(+)$ Nicotine di (-) tartrate was the kind gift of Dr R. B. Barlow, Department of Pharmacology, University of Edinburgh.

Samples of mixed-function oxidase inhibitors SKF 525A, SKF 330IA, SKF 7997 A, metopirone base and diphenylpropylacetic acid were the kind gifts of Dr P. D. G. Dean of this department.

Authentic carotenoids. $\beta$-Carotene, lycopene and zeaxanthin were kindly provided by F. Hoffmann-La Roche \& Co. Ltd, Basle, Switzerland. $\beta$-Cryptoxanthin and rubixanthin respectively were obtained from the fruits of Cyphomandra betaceae and rose hips obtained from the University of Liverpool Botanic Gardens, Ness, through the courtesy of the Director, Mr J. K. Hulme. Both compounds were purified by standard techniques (Britton \& Goodwin, I97I).

Culture conditions. Flavobacterium strains were grown in liquid culture on a medium containing (g/l):glucose, 5g; Bacto-yeast extract (Difco), Io g; Bacto tryptone, $10 \mathrm{~g} ; \mathrm{NaCl}$, $30 \mathrm{~g} ; \mathrm{MgSO}_{4} \cdot 7 \mathrm{H}_{2} \mathrm{O}, 5 \mathrm{~g}$; the final $\mathrm{pH}$ being adjusted to $7 \cdot 2$ by addition of a small amount of $\mathrm{NaOH}$ before autoclaving at $\mathrm{Io} \mathrm{lb} / \mathrm{in}^{2}$ for Io min. Cultures were maintained on slopes of the above medium supplemented with $3 \%$ Bacto-agar.

The bacteria were normally grown in liquid medium $(50 \mathrm{ml})$ in $250 \mathrm{ml}$ conical flasks modified by four indentations acting as baffles to increase aeration of the cultures. Cultures were inoculated either from slopes or with $\mathrm{I} \mathrm{ml}$ of a $24 \mathrm{~h}$ liquid culture, and were shaken (I60 rev./min) in an orbital incubator (Gallenkamp) illuminated with fluorescent light (about $200 \mathrm{ft}$-candles), usually for 40 to $44 \mathrm{~h}$. Strain RI5I9 was grown at 19 to $2 \mathrm{I}{ }^{\circ} \mathrm{C}$, the other strains at $26^{\circ} \mathrm{C}$.

Addition of inhibitors. Appropriate amounts of $\mathrm{CaCl}_{2} \cdot 6 \mathrm{H}_{2} \mathrm{O}$ were included in the liquid medium before autoclaving.

Solid alkaloid salts and mixed-function oxidase inhibitors were dissolved in sterile water containing sufficient dimethyl sulphoxide to give a final concentration of $0.4 \%$ dimethyl sulphoxide in the cultures.

Diphenylamine (DPA) was dissolved in ethanol at concentrations such that $\mathrm{I} \mathrm{ml}$ of ethanolic solution added to a $50 \mathrm{ml}$ culture resulted in the required final DPA concentration. 
Nicotine analogues supplied as salts were converted to the free bases before use.

All liquid additives and solutions were introduced into cultures by sterile pipette at the time of inoculation.

The final overall concentrations of inhibitors in cultures were as shown in Table $\mathrm{r}$.

Incubation with $\left[2-{ }^{14} \mathrm{C}\right]$ mevalonic acid. $\left[2-{ }^{14} \mathrm{C}\right]$ Mevalonic acid lactone ( $\mu \mathrm{Ci} / 50 \mathrm{ml}$ culture) (Radiochemical Centre, Amersham, Buckinghamshire) was converted into the potassium salt by the standard method (Britton \& Goodwin, I97I). Sterile aqueous solutions of potassium mevalonate were added to Flavobacterium cultures by sterile pipette at the time of inoculation.

Extraction and purification of carotenoids. Flavobacterium organisms were harvested by centrifugation at $10000 \mathrm{~g}$ for $10 \mathrm{~min}$. Carotenoids were extracted from them with cold acetone, or in the case of nicotine-inhibited organisms containing lycopene, warm methanol followed by acetone. No mechanical disruption of the organisms was necessary. Debris was dried at $110^{\circ} \mathrm{C}$ and its dry wt determined. The lipid extracts were transferred to diethyl ether-light petroleum (b.p. 40 to $\left.60^{\circ} \mathrm{C}\right)(\mathrm{I}: \mathrm{I})$, washed with water, evaporated and chromatographed in light petroleum on a column of neutral alumina (Woelm) deactivated to Brockmann grade III by the addition of $6 \%(\mathrm{w} / \mathrm{w})$ water in the normal way (Britton \& Goodwin, I97I). Three fractions (I-III) were usually collected, eluted respectively with $2 \%(\mathrm{v} / \mathrm{v})$ diethyl ether in light petroleum, $50 \%$ diethyl ether in light petroleum and $2 \%$ ethanol in diethyl ether. Fraction I contained carotenoid hydrocarbons, and was chromatographed on thin layers of silica gel $\mathrm{G}$ (Merck) with $0.5 \%$ diethyl ether in light petroleum as developing solvent. Any $\beta$-carotene $\left(R_{F} 0.6\right)$ or lycopene $\left(R_{F} 0.5\right)$ present were eluted with diethyl ether and rechromatographed on thin layers of magnesium oxide-Kieselguhr $G(\mathrm{I}: \mathrm{I}, \mathrm{w} / \mathrm{w})$, $\beta$-carotene in $5 \%$ acetone in light petroleum, and lycopene in acetone-benzene-light petroleum (2:2:I). The $\beta$-carotene chromatograms were examined under u.v. light for the presence of phytoene and phytofluene. In quantitative work, $\beta$-carotene and lycopene were estimated at this stage. For mass spectrometric and n.m.r. identification, and in radioisotope experiments, these compounds were given further purification by t.l.c. on silica gel $\mathrm{G}$ with $5 \%$ benzene in light petroleum as developing solvent.

Fraction II, which contained monohydroxycarotenoids, was chromatographed on silica gel $\mathrm{G}$ with $50 \%$ diethyl ether in light petroleum as developing solvent, and any coloured band present was eluted with diethyl ether and rechromatographed on $\mathrm{MgO}-\mathrm{Kieselguhr} \mathrm{G}$ with $40 \%$ acetone in light petroleum to separate $\beta$-cryptoxanthin $\left(R_{F} 0.8\right)$ and rubixanthin $\left(R_{F} 0 \cdot 4\right)$. These were assayed quantitatively at this stage and, when necessary, further purified by t.l.c. on silica gel $\mathrm{G}$ with $40 \%$ diethyl ether in light petroleum as solvent, for mass spectrometry or radioassay.

Fraction III (dihydroxycarotenoids) was chromatographed on thin layers of silica gel G with diethyl ether as developing solvent, and the zeaxanthin band obtained was rechromatographed on MgO-Kieselguhr G (I:I) in $30 \%$ acetone in light petroleum, for quantitative assay. For mass spectrometry and radioisotope experiments the zeaxanthin was further purified by t.l.c. on silica gel $\mathrm{G}$ with $8 \%(\mathrm{v} / \mathrm{v})$ methanol in benzene or $25 \%(\mathrm{v} / \mathrm{v})$ ethyl acetate in carbon tetrachloride as developing solvents.

Acetylation. Rubixanthin and zeaxanthin samples were acetylated by the acetic anhydridepyridine method (Britton \& Goodwin, 197I), and the acetates were purified by t.l.c. first on silica gel $\mathrm{G}$ in $20 \%$ diethyl ether in light petroleum, and then on $\mathrm{MgO}-$ Kieselguhr $\mathrm{G}$ (I:I) with $25 \%$ acetone in light petroleum (rubixanthin acetate) or $20 \%$ acetone in light petroleum (zeaxanthin diacetate).

Determination of spectra. Electronic absorption spectra were determined, in light petroleum 
(hydrocarbons) or ethanol (xanthophylls), with a Unicam SP 800 recording spectrophotometer. Carotenoids were estimated quantitatively from the spectra by the method of Davies (I965), using the $E_{1 \mathrm{~cm}}^{1 \%}$ values given by Davies.

Mass spectra were determined by Mrs A. M. Ball in an A.E.I. MS I2 instrument, at $70 \mathrm{eV}, 200$ to $220^{\circ} \mathrm{C}$.

Electron microscopy. Electron microscopic examination of Flavobacterium R I 519 cells was kindly undertaken by Mrs J. Wood through the courtesy of Dr C. Green of this department.

Radioassay. Purified samples were dissolved in $5 \mathrm{ml}$ toluene, bleached by u.v. irradiation and transferred to clean vials, to which $5 \mathrm{ml}$ of liquid scintillator solution ( $10 \mathrm{~g} 2,5$-di-

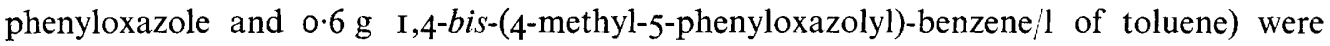
added. The samples were assayed for radioactivity in a Beckman LS 200 liquid scintillation counter.

\section{RESULTS AND DISCUSSION}

Several substances have been shown to inhibit production of the normal carotenoids in one or more species of bacteria and fungi. The effects of some of these substances on growth, and carotenoid biosynthesis in Flavobacterium R I519, an organism which normally produces zeaxanthin as virtually its only carotenoid, have been studied (Table I).

The inhibitor best known and most widely used in carotenoid studies is diphenylamine (DPA). DPA has been shown to inhibit production of the normal carotenoids, and to cause an accumulation of the probable biosynthetic intermediate, phytoene $\left(7,8, \mathrm{II}, \mathrm{I}_{2}, 7^{\prime}, 8^{\prime}, \mathrm{II}^{\prime}\right.$, $12^{\prime}$-octahydro- $\psi, \psi$-carotene) (IV) in many organisms, e.g. Neurospora crassa (Turian, 1957), Phycomyces blakesleeanus (Goodwin, Jamikorn \& Willmer, 1953), Blakeslea trispora (Thomas \& Goodwin, 1967), Verticillium albo-atrum (Valadon \& Mummery, 1966), Rhodospirillum rubrum (Goodwin \& Osman, 1954), Mycobacterium phlei (Goodwin, I953; Rilling, I965), Flavobacterium dehydrogenans (Weeks, 1971). Moreover, in some cases, removal of the DPA by washing allows synthesis of the normal carotenoids to proceed, often at the expense of the accumulated phytoene (Goodwin \& Osman, I954; Valadon \& Mummery, I966; Davies, Villoutreix, Williams \& Goodwin, 1963). From studies of the kinetics of synthesis of the normal carotenoids in cultures of Rhodospirillum rubrum from which the DPA had been removed by washing, Liaaen-Jensen, Cohen-Bazire, Nakayama \& Stanier (1958) were able to postulate schemes for the biosynthesis of spirilloxanthin, the normal major carotenoid of $R$. rubrum.

DPA thus acts by inhibiting the desaturation reaction of carotenoid biosynthesis (Turian, 1957; Rilling, 1965), and, because of this effect, has proved to be very useful in studies of carotenoid biosynthesis.

However, at no DPA concentration was any specific inhibition of zeaxanthin synthesis observed, or any production of phytoene detected, in Flavobacterium R I5I9 (Table I); DPA is thus not a suitable inhibitor for use in studies of zeaxanthin biosynthesis in Flavobacterium RI5I9.

One outstanding problem in zeaxanthin biosynthesis is whether hydroxylation occurs at an early or a late stage. A substance which specifically inhibited the hydroxylation reaction would therefore be very useful in causing the accumulation of the prehydroxylation intermediate. Stereochemical studies (J. C. B. McDermott, F. J. Leuenberger, G. Britton and T. W. Goodwin, unpublished results) indicated that the hydroxylation probably involves a mixed-function oxidase type of enzyme, thus suggesting the use of a mixed-function oxidase inhibitor. Hammond \& White (1970) have reported that several such inhibitors 
Table I. Summary of the effects of various substances on growth and carotenoid synthesis in Flavobacterium R I 519

\begin{tabular}{|c|c|c|c|}
\hline Substance & Concentration & Inhibition of growth & Carotenoids present \\
\hline Diphenylamine & $\begin{array}{l}\mathrm{I} \times 10^{-3} \mathrm{M}, \mathrm{I} \times 10^{-1} \mathrm{M} \\
\mathrm{I} \times 10^{-5} \mathrm{M}, \mathrm{I} \times 10^{-6} \mathrm{M} \\
\mathrm{I} \times 10^{-7} \mathrm{M},\end{array}$ & $\begin{array}{l}\text { Complete } \\
\text { Partial } \\
\text { None }\end{array}$ & $\begin{array}{l}\text { None } \\
\text { Zeaxanthin }(100 \%) \\
\text { Zeaxanthin }(100 \%)\end{array}$ \\
\hline $\begin{array}{l}\text { SKF } 525 \mathrm{~A} \\
\text { SKF 330 I A } \\
\text { Metopirone base }\end{array}$ & $\begin{array}{l}0.01 \%, 0.005 \% ! \\
0.01 \%, 0.005 \% ! \\
0.01 \%, 0.005 \% !\end{array}$ & Complete & None \\
\hline $\begin{array}{l}\text { Diphenylpropylacetic acid } \\
\text { Piperonyl butoxide } \\
\text { SKF } 7997-A_{3}\end{array}$ & $\left.\begin{array}{ll}0.01 \%, 0.005 \% \\
0.04 \%, 0.01 \% \\
0.01 \%, 0.005 \%\end{array}\right\}$ & Slight & Zeaxanthin $(100 \%)$ \\
\hline $\mathrm{CaCl}_{2} \cdot 6 \mathrm{H}_{2} \mathrm{O}$ & $\begin{array}{l}2.0 \% \\
1.0 \%\end{array}$ & $\begin{array}{l}\text { Considerable } \\
\text { Partial }\end{array}$ & $\begin{array}{l}\text { Very little, mainly zeaxanthin } \\
\text { Zeaxanthin }(80 \%), \beta \text {-caro- } \\
\text { tene }(10 \%), \beta \text {-cryptoxanthin } \\
(10 \%)\end{array}$ \\
\hline$(-)$ Nicotine & $\begin{array}{l}0.5 \%, 0.1 \% \\
5.0 \mathrm{~mm}\end{array}$ & $\begin{array}{l}\text { None } \\
\text { Very slight }\end{array}$ & $\begin{array}{l}\text { Zeaxanthin }(100 \%) \\
\text { Lycopene }(95 \%) \text {, traces } \\
\text { zeaxanthin, rubixanthin }\end{array}$ \\
\hline & $3.75 \mathrm{~mm}$ & None & $\begin{array}{c}\text { Lycopene }(54 \%) \text {, rubixanthin } \\
(42 \%) \text {, zeaxanthin (trace) }\end{array}$ \\
\hline & $1.0 \mathrm{~mm}$ & None & $\begin{array}{l}\text { Rubixanthin }(60 \%) \text {, zea- } \\
\text { xanthin }(35 \%) \text {, lycopene } \\
\text { (trace) }\end{array}$ \\
\hline$(+)$ Nicotine & $5.0 \mathrm{~mm}$ & Very slight & $\begin{array}{l}\text { Lycopene }(80 \%) \text {, rubi- } \\
\text { xanthin }(5 \%) \text {, zeaxanthin } \\
(10 \%)\end{array}$ \\
\hline Nicotyrine & $2.5 \mathrm{~mm}$ & Partial & Zeaxanthin $(100 \%)$ \\
\hline Nor-nicotyrine & $0.65 \mathrm{mM}$ & Partial & Zeaxanthin $(100 \%)$ \\
\hline Nor-nicotine & $3.75 \mathrm{mM}$ & Slight & $\begin{array}{c}\text { Rubixanthin }(84 \%) \\
\text { zeaxanthin }(12 \%)\end{array}$ \\
\hline Myosmine & $2.5 \mathrm{mM}$ & Partial & Zeaxanthin $\left(100^{\circ}\right)$ \\
\hline $\begin{array}{l}\text { Anabasine } \\
\text { Quinine sulphate }\end{array}$ & $5.0 \mathrm{~mm}$ & Partial & Zeaxanthin $(100 \%)$ \\
\hline $\left.\begin{array}{l}\text { Quinidine sulphate } \\
\text { Brucine sulphate }\end{array}\right\}$ & $5.0 \mathrm{~mm}$ & Complete & None \\
\hline $\begin{array}{l}\text { Atropine sulphate } \\
\text { Hyoscyamine sulphate }\end{array}$ & & & \\
\hline $\begin{array}{l}\text { Pilocarpine hydrochloride } \\
\text { Scopolamine hydrobromide } \\
\text { Strychnine sulphate }\end{array}$ & $5.0 \mathrm{~mm}$ & Partial & Zeaxanthin $\left(100^{\circ}\right)$ \\
\hline $\left.\begin{array}{l}\text { 3-Picoline } \\
\text { Morpholine } \\
\text { Pyridine }\end{array}\right\}$ & $5.0 \mathrm{~mm}$ & Slight & Zeaxanthin $\left(100^{\circ}\right)$ \\
\hline $\begin{array}{l}\text { 3-Ethylpyridine } \\
\text { 5-Ethyl-3-methylpyridine }\end{array}$ & $5.0 \mathrm{~mm}$ & Complete & None \\
\hline
\end{tabular}

prevented the formation of the normal polar carotenoids in Staphylococcus aureus, and led instead to the accumulation of carotene hydrocarbons.

The effect of some of these compounds (SKF 525A, SKF 330 IA, metopirone base, diphenylpropylacetic acid, piperonyl butoxide and SKF 7997- $\mathrm{A}_{3}$ ) on zeaxanthin production in Flavobacterium RI5I9 was therefore studied (Table I), but in no case was it possible to demonstrate specific inhibition of zeaxanthin synthesis and accumulation of any other carotenoid in its place. It thus appears that mixed-function oxidase inhibitors are not of use as inhibitors of zeaxanthin biosynthesis in cultures of Flavobacterium R I5I9.

Earlier work during studies of the stereochemistry of zeaxanthin biosynthesis in Flavobacterium RI5I9 had established that the inclusion of small amounts of $\mathrm{Ca}^{2+}$ in the culture 


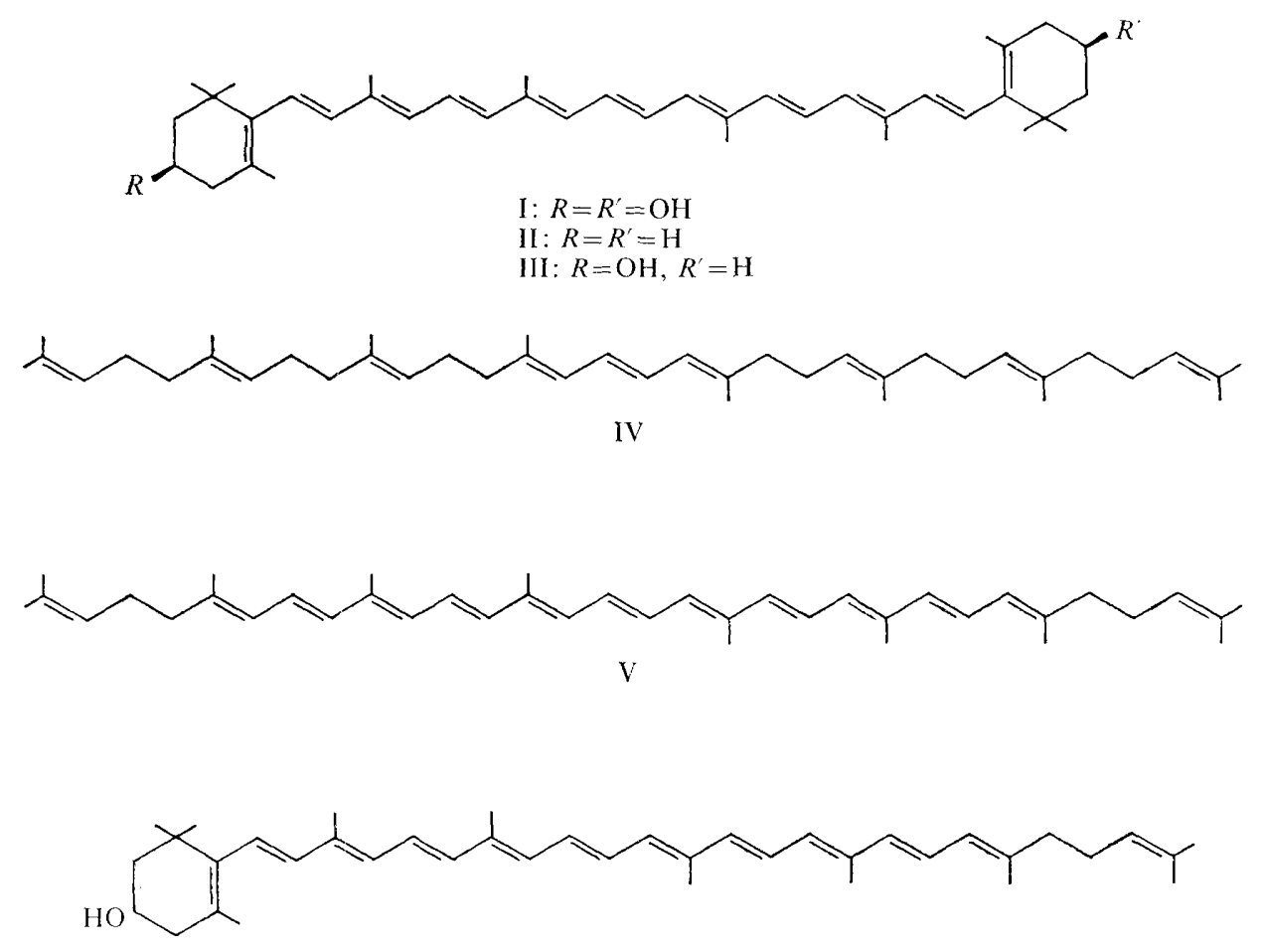

VI

medium resulted in a slight decrease in zeaxanthin production and allowed the detection of small amounts of $\beta$-carotene ( $\beta, \beta$-carotene) (II) and $\beta$-cryptoxanthin ( $\beta, \beta$-caroten-3-ol) (III). The effect of $\mathrm{Ca}^{2+}$ at different concentrations and under different incubation conditions was therefore studied.

At low $\mathrm{Ca}^{2+}$ concentrations (below $0.5 \%, \mathrm{w} / \mathrm{v}, \mathrm{CaCl}_{2} .6 \mathrm{H}_{2} \mathrm{O}$ ) no effect on growth or carotenogenesis was observed; $2 \% \mathrm{CaCl}_{2} .6 \mathrm{H}_{2} \mathrm{O}$ markedly inhibited growth and carotenogenesis. At $\mathrm{I} \% \mathrm{CaCl}_{2} \cdot 6 \mathrm{H}_{2} \mathrm{O}$, some change in carotenoid composition occurred, especially if the bacteria were cultured in normal conical flasks, rather than 'baffled' flasks, in order to diminish the aeration. Under these conditions, $\beta$-carotene and $\beta$-cryptoxanthin each constituted about Io $\%$ of the total carotenoid content, but growth was somewhat lessened.

The accumulation of $\beta$-carotene and $\beta$-cryptoxanthin suggests that these compounds may be intermediates in zeaxanthin biosynthesis, though they could be side products which appear only under abnormal conditions. However, the inhibition of zeaxanthin biosynthesis was not sufficient to be of use in further series of experiments.

Recently two compounds have been shown, in several biological systems, to inhibit production of the normal carotenoids and cause an accumulation of lycopene ( $\psi^{\prime}, \psi^{\prime}$-carotene) (V). In several higher plants, especially citrus species, and fungi (Phycomyces blakesleeanus, Blakeslea trispora), 2-(4-chlorophenylthio) triethylamine hydrochloride (CPTA) caused the accumulation of lycopene in place of the normal carotenoid complement (Coggins, Henning \& Yokoyama, I970; Yokoyama, Coggins \& Henning, I97I; Hsu, Yokoyama \& Coggins, I972; Yokoyama, De Benedict, Coggins \& Henning, 1972). A similar effect was observed in cultures of Mycobacterium marinum grown in the presence of nicotine (Howes \& Batra, 
I970); the normal main pigment, $\beta$-carotene, was replaced by lycopene. CPTA and nicotine are therefore thought to inhibit the cyclization reaction in carotenoid biosynthesis, and the accumulation of lycopene rather than neurosporene has been taken to indicate that lycopene is the substrate of this reaction. If cyclization is inhibited by nicotine or CPTA in Flavobacterium 0147 , then production of zeaxanthin should be prevented, and in its place the precyclization intermediate would be expected to accumulate. Identification of the intermediate as a hydroxy compound or a hydrocarbon should then indicate whether hydroxylation occurs before or after cyclization.

Nicotine was therefore tested for any inhibitory effect on zeaxanthin formation in Flarobacterium or 47 , initially at the concentration ( $5 \mathrm{~mm}$ ) used by Howes \& Batra (1970). It was immediately apparent that a change in pigmentation had occurred, since the cultures grown in the presence of nicotine were dull reddish-pink in contrast to the yellow of normal cultures. This was confirmed by chromatographic examination of the pigment extracts of the two cultures. Whereas the normal organisms contained zeaxanthin as essentially the only pigment, only traces of zeaxanthin were detected in nicotine-grown organisms. In these the main pigment was a hydrocarbon, which was identified as lycopene by comparison of its chromatographic properties, electronic absorption spectrum and mass spectrum with those of authentic lycopene. No other carotenoids were detected in more than trace amounts; in particular, no compound was detected with the chromatographic properties expected for the mono- or dihydroxylycopene which might have been expected if hydroxylation normally occurred before cyclization. These findings thus suggest that cyclization precedes hydroxylation in the biosynthetic pathway.

Because the inhibition of zeaxanthin synthesis was virtually complete at $5 \mathrm{~mm}$-nicotine the effect of a lower concentration (I $\mathrm{mm}$ ) was examined. At this nicotine concentration, zeaxanthin synthesis was again largely inhibited, but only a very small amount of lycopene was present. The major carotenoid which replaced zeaxanthin had the chromatographic properties of a monohydroxycarotenoid, and was identified as rubixanthin ( $\beta, \psi$-caroten-3ol) (VI) by comparison of its chromatographic properties, electronic absorption spectrum and mass spectrum with those of rubixanthin isolated from rose hips, and by similar comparison of its acetate with rubixanthin acetate. This could suggest that rubixanthin is an intermediate in zeaxanthin biosynthesis, but probably indicates that, under the abnormal conditions of nicotine culture, inhibition of cyclization and hydroxylation at one end of the carotenoid molecule is essentially complete before appreciable inhibition of cyclization occurs at the other end of the molecule.

The effects of $7.5 \mathrm{~mm}$-nicotine on growth and on the time course of pigment production (Fig. I, 2) were that the total organism dry wt was always slightly lower, but the total pigment produced was higher, in the nicotine-grown cultures than in normal cultures. The total carotenoid concentration ( $\mu \mathrm{g} / \mathrm{g}$ dry wt) was usually more than $30 \%$ greater in nicotinegrown than in normal cultures. Such a stimulatory effect of nicotine on total carotenoid production has also been observed in cultures of several photosynthetic bacteria (A. BenAziz, R. K. Singh, G. Britton \& T. W. Goodwin, unpublished results).

Throughout this work it was found that the extraction of lycopene from nicotine-inhibited cells was much more difficult than the extraction of zeaxanthin from normal cells, or of zeaxanthin, rubixanthin and $\beta$-cryptoxanthin from nicotine-inhibited cells. The lycopene thus appeared to be much more firmly bound within the organisms. No apparent differences were revealed, however, by electron-microscopic examination of normal and $5 \mathrm{~mm}$-nicotineinhibited organisms, not even in the walls and membranes, where carotenoids of nonphotosynthetic bacteria are generally believed to be located (Sistrom, I959; Salton \& 


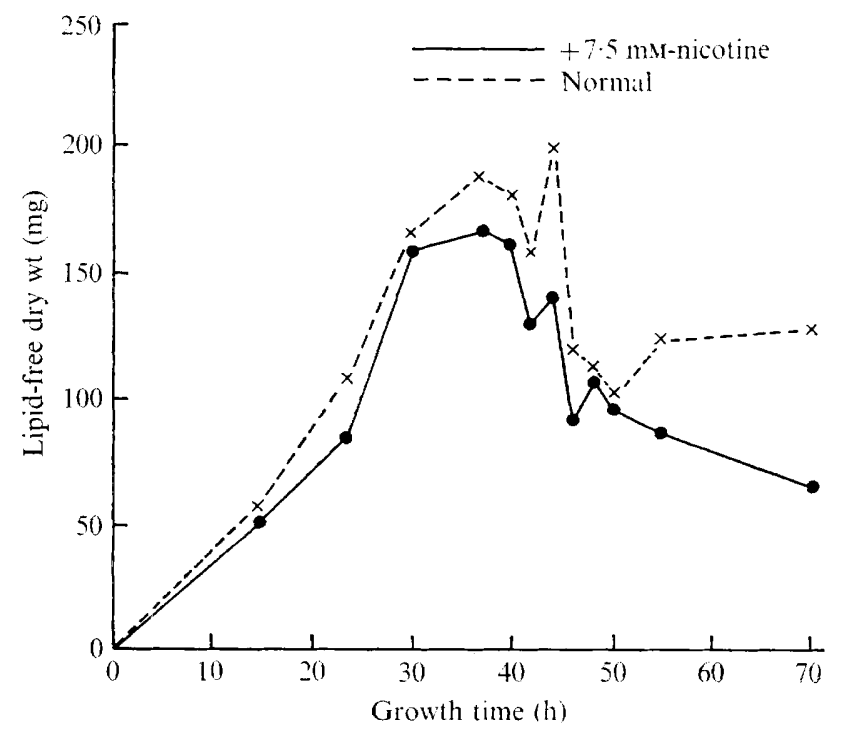

Fig. I. Comparison of variation of lipid-free organism dry wt with growth time for normal and nicotine-grown $(7.5 \mathrm{~mm})$ cultures of Flavobacterium R1519.

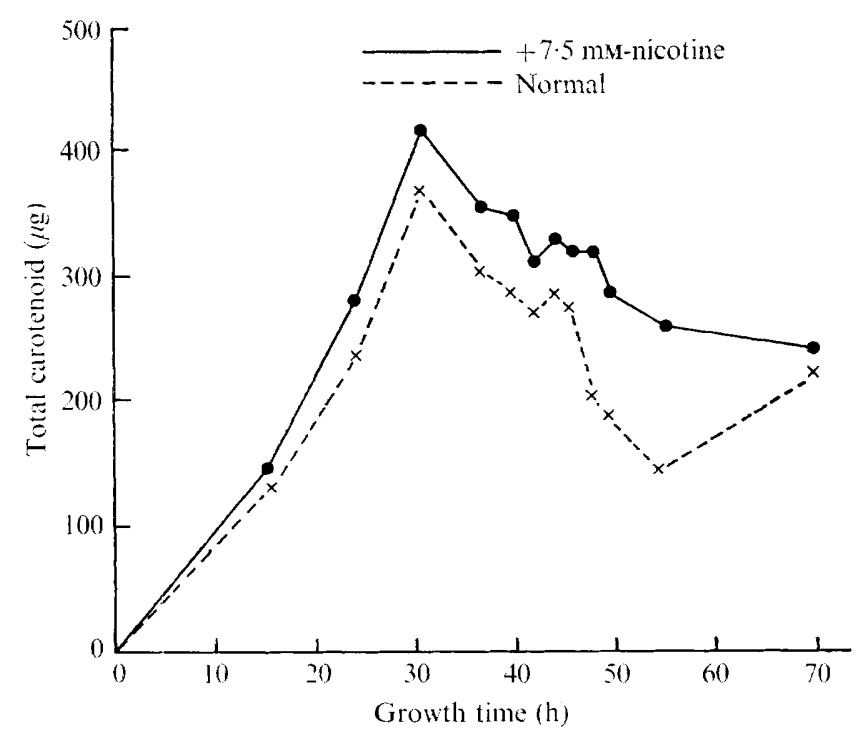

Fig. 2. Comparison of variation of total carotenoid with growth time for normal and nicotinegrown ( $7.5 \mathrm{~mm})$ cultures of Flavobacterium RI 519.

Ehtisham-Ud-Din, 1965; Stoeckenius \& Rowen, I967; Work \& Griffiths, I968; Steensland \& Larsen, 1969; Eberhardt, I97I).

The inhibition of zeaxanthin production was observed only with Flavobacterium R I5I9, a low temperature ( 20 to $22^{\circ} \mathrm{C}$ ) bacterium derived from a Norwegian parent, and not with several other zeaxanthin-producing Flavobacterium strains (RI534, RI552, RI560) derived from a higher temperature $\left(26\right.$ to $28^{\circ} \mathrm{C}$ ) African parent. 
Table 2. Incorporation of $\left[2-{ }^{14} \mathrm{C}\right]$ mevalonic acid into carotenoids in normal and nicotine-inhibited cultures of Flavobacterium RI5I9

Cultures $(50 \mathrm{ml})$ were grown for $40 \mathrm{~h}$ with $\left[2-{ }^{14} \mathrm{C}\right]$ potassium mevalonate $(\mathrm{I} \mu \mathrm{Ci})$, and nicotine as indicated.

\begin{tabular}{|c|c|c|c|c|c|c|}
\hline \multirow{2}{*}{$\begin{array}{l}\text { Nicotine } \\
\text { added }\end{array}$} & \multicolumn{2}{|c|}{ Lycopene } & \multicolumn{2}{|c|}{ Rubixanthin } & \multicolumn{2}{|c|}{ Zeaxanthin } \\
\hline & $\mu \mathrm{g}$ & d.p.m. & $\mu \mathrm{g}$ & d.p.m. & $\mu \mathrm{g}$ & d.p.m. \\
\hline None & - & - & - & 一 & 372 & 40240 \\
\hline $\mathrm{I} .0 \mathrm{mM}$ & - & - & 174 & 13840 & 241 & 11584 \\
\hline $7.5 \mathrm{mM}$ & 309 & I 3570 & 70 & 3790 & 3 & IIO \\
\hline
\end{tabular}

VII: $R=\overbrace{\substack{\mathrm{N} \\ \mathrm{CH}_{3}}}$

$\mathrm{IX}: R=$<smiles>CC1=NCCC1</smiles>

$\mathrm{XI}: R=$<smiles>Cc1ccc[nH]1</smiles>

FIII: $R=$<smiles>CC1CCCCN1</smiles>

$X: R=$<smiles>CC1CCCN1C</smiles>

XII: $R=$<smiles>Cc1ccc[nH]1</smiles>

Flavobacterium $\mathrm{R} 15 \mathrm{I} 9$ efficiently incorporated $\left[2{ }^{14} \mathrm{C}\right]$ mevalonate into zeaxanthin in normal cultures and into lycopene and rubixanthin in nicotine-inhibited cultures. (Table 2).

Several alkaloids, substituted pyridines and compounds structurally similar to nicotine were examined for inhibitory effects on zeaxanthin synthesis, to determine whether the inhibition of cyclization was specific to nicotine or other related compounds acted similarly (Table I).

No specific inhibitory effect on zeaxanthin biosynthesis was observed for any of the alkaloids or substituted pyridines tested.

Several compounds with structures very similar to nicotine (VII) were then tested. Most of these did not affect carotenoid biosynthesis, zeaxanthin remaining virtually the only pigment in cultures grown in the presence of anabasine (VIII), myosmine (IX), nicotyrine (X) and nor-nicotyrine (XI). In cultures grown in the presence of $3.75 \mathrm{~mm}$-nor-nicotine (XII) however, rubixanthin $(84 \%)$ replaced zeaxanthin as the main carotenoid. Nor-nicotine was thus also an inhibitor of carotenoid cyclization, although at this concentration, the degree 
of inhibition was less than with nicotine. Concentrations of any of these compounds above 2 to $3 \mathrm{~mm}$ seriously inhibited bacterial growth.

The work on the inhibition by nicotine had all been with the naturally occurring (-) enantiomer; it was found that zeaxanthin biosynthesis was inhibited to approximately the same extent by the unnatural $(+)$ isomer.

Thus the inhibition of carotenoid cyclization by nicotine had considerable specificity. Although both optical isomers of nicotine were inhibitory, absence of the $N$-methyl group (as in nor-nicotine) reduced the inhibition, and the minor modifications in anabasine, myosmine, nicotyrine and nor-nicotyrine resulted in a complete loss of inhibition. Unfortunately, only small amounts of these nicotine-like compounds were available, allowing in most cases only a single small-scale experiment, so that this potentially interesting aspect of nicotine inhibition could not be studied further.

The nicotine inhibition in Flavobacterium R $15 \mathrm{I} 9$ of the cyclization reaction of carotenoid biosynthesis, especially in combination with isotopic labelling, promises to be very useful for elucidating details of the pathways of zeaxanthin biosynthesis in Flavobacterium R I 5I9.

We are grateful to F. Hoffman-La Roche \& Co. Ltd, Basle, Switzerland, for financial support, cultures for Flavobacterium strains and samples of authentic carotenoids, and to the Science Research Council for financial support. We thank Misses Margaret Sinclair, Tina King and Margaret McLaurin for assistance at various stages of the work. We are grateful to Dr P. P. Batra for allowing us prepublication access to his results on nicotine inhibition in Mycobacteria.

\section{REFERENCES}

Britton, G. (1971). General aspects of carotenoid biosynthesis. In Aspects of Terpenoid Chemistry and Biochemistry, pp. 255-289. Edited by T. W. Goodwin. London: Academic Press.

Britton, G. \& Goodwin, T. W. (I971). Biosynthesis of carotenoids. In Methods in Enzymology 18C, 654-70I.

Coggins, C. W., Jun., Henning, G. L. \& Yokoyama, H. (1970). Lycopene accumulation induced by 2-(4-chlorophenylthio)-triethylamine hydrochloride. Science, New York 168, I 589-I 590.

Davies, B. H. (1965). Analysis of carotenoid pigments. In Chemistry and Biochemistry of Plant Pigments, pp. 489-532. Edited by T. W. Goodwin. London: Academic Press.

Davies, B. H., Villoutreix, J., Williams, R. J. H. \& Goodwin, T. W. (1963). The possible role of $\beta$-zeacarotene in carotenoid synthesis. Biochemical Journal 89, $96 \mathrm{P}$.

Eberhardt, U. (I97I). The cell wall as the site of carotenoid in the 'Knallgas' bacterium, I $2 / 60 / x$. Archiv fïr Mikrobiologie 8o, 32-37.

Goodwin, T. W. (1953). The biogenesis of carotenoids. Journal of the Science of Food \& Agriculture 5, 209-220.

Goodwin, T. W. (1971). Biosynthesis. In Carotenoids, pp. 577-636. Edited by O. Isler. Basel: Birkhäuser Verlag.

Goodwin, T. W., JAmikorn, M. \& Willmer, J. S. (I953). Studies on carotenogenesis. 7. Further observations concerning the action of diphenylamine in inhibiting the synthesis of $\beta$-carotene in Phycomyces blakesleanus. Biochemical Journal 53, $53 \mathrm{I}-538$.

Goodwin, T. W. \& Osman, H. G. (1954). Studies in carotenogenesis. Io. Spirilloxanthin synthesis by washed cells of Rhodospirillum rubrum. Biochemical Journal 56, 220-230.

Hammond, R. K. \& WhITE, D. C. (1970). Inhibition of carotenoid hydroxylation in Staphylococcus aureus by mixed-function oxidase inhibitors. Journal of Bacteriology 103, 607-610.

Howes, C. D. \& Batra, P. P. (1970). Accumulation of lycopene and inhibition of cyclic carotenoids in Mycobacterium in the presence of nicotine. Biochimica et biophysica acta 222, 174-178.

Hsu, W.-J., Yokoyama, H. \& Coggins, C. W., Jun. (1972). Carotenoid biosynthesis in Blakeslea trispora. Phytochemistry, II, 2985-2990.

Liafen-Jensen, S., Cohen-Bazire, G., Nakayama, T. O. M. \& Stanier, R. Y. (1958). The path of carotenoid synthesis in a photosynthetic bacterium. Biochimica et biophysica acta 29, 477-498. 
Mathews, M. M. \& Sistrom, W. (1959). Intracellular location of carotenoid pigments and some respiratory enzymes in Sarcina lutea. Journal of Bacteriology 78, 778-787.

Porter, J. W. \& Anderson, D. G. (1967). Biosynthesis of carotenes. Annual Review of Plant Physiology r8, 197--228.

RilLing, H. C. (1965). A study of inhibition of carotenoid synthesis. Archives of Biochemistry and Biophysics I10, 39-46.

Salton, M. R. J. \& Ehtisham-Ud-Din, A. F. M. (1965). Localization of cytochromes and carotenoids in isolated bacterial membranes. Australian Journal of Experimental Biology and Medical Science 43, $255^{-264}$

SteensLAnd, H. \& LaRSEn, H. (1969). A study of the cell envelope of the halobacteria. Journal of General Microbiology 55, 325-336.

Stoeckenius, W. \& Rowen, R. (1967). A morphological study of Halobacterium halobium and its lysis in media of low salt concentration. Journal of Cell Biology 34, 365-393.

Thomas, D. M. \& Goodwin, T. W. (1967). Studies on carotenogenesis in Blakeslea trispora. I. General observations on synthesis in mated and unmated strains. Phytochemistry 6, 355-360.

TURIAN, G. (1957). Recherches sur l'action anticaroténogène de la diphénylamine et ses conséquences sur la morphogenèse reproductive chez Allomyces et Neurospora. Physiologia plantarum 1o, 667-674.

VAladon, L. R. G. \& MUMmery, R. S. (1966). Inhibition of carotenoid synthesis in a mutant of Verticillium albo-atrum. Journal of General Microbiology 45, 531 -540.

Walton, T. J., Britton, G. \& Goodwin, T. W. (1969). Biosynthesis of xanthophylls in higher plants: stereochemistry of hydroxylation at C-3. Biochemical Journal II2, 383-385.

WEEKS, O. B. (1971). Biosynthesis of $\mathrm{C}_{50}$ carotenoids. In Aspects of Terpenoid Chemistry and Biochemistry, pp. 291-314. Edited by T. W. Goodwin. London: Academic Press.

Work, E. \& GRIFFITHS, H. (1968). Morphology and chemistry of cell walls of Micrococcus radiodurans. Journal of Bacteriology 95, 64[-657.

Yokoyama, H., Coggins, C. W., Jun. \& Henning, G. L. (1971). The effect of 2-(4-chlorophenylthio)triethylamine hydrochloride on the formation of carotenoids in citrus. Phytochemistry 10, I 83I-I 834.

Yokoyama, H., De Benedict, C., Coggins, C. W., Jun. \& Henning, G. L. (I972). Induced colour changes in grapefruit and orange. Phytochemistry Ir, $1721-1728$. 